\title{
Estiagem e alterações das funções hidrológicas: o caso do reservatório de Atibainha
}

\author{
Vania Rosa Pereira* \\ José Teixeira Filho**
}

\begin{abstract}
Resumo
Este artigo é um resultado de pesquisa, e tem como objetivo identificar a relação entre o uso do solo e o rendimento de água. A área de estudo é a bacia hidrográfica de Atibainha $(140 \mathrm{~km} 2)$ que, juntamente com mais 3 bacias hidrográficas, abastece cerca de 13 milhões de pessoas na cidade de São Paulo e Campinas. Os mapas de uso da terra foram obtidos a partir de 1988, 1993, 1996, 2001 e 2008 de acordo com a classificação de cenas Landsat. A análise hidrológica foi derivada de 30, 45, 60 e 75 fluxos diários de vazão mínima absoluta, juntamente à precipitação total de água durante os anos de 1986 e 2007. Análises de regressão linear e dados estatísticas não-paramétricos foram utilizados para identificar as mudanças temporais no desempenho e tendência de precipitação. Os resultados indicaram que a mata atlântica secundária diminui a queda de $38 \%$ para $21 \%$ e o arborização com Eucalyptus urophylla aumentou de $24 \%$ para $43 \%$. O total de precipitação anual mostrou uma tendência de queda significativa $(p<0,001)$. Durante o mesmo período, a descarga seca diária apresentou uma tendência de declínio na importância de 30, 45, 60 e 75 dias secos consecutivos, apresentando um decréscimo de $61 \%$, 56\%, $55 \%$ e $60 \%$, respectivamente $(p<0,001)$. Os resultados indicam que existe uma tendência de queda de rendimento de água durante a estação seca na bacia do Atibainha e isso está diretamente relacionado com a diminuição dos processos de precipitação.
\end{abstract}

Palavras - chave: desmatamneto, reflorestamento, impacto ambiental, periodo de estiagem. Abstract

This paper is a research result, which objective is to identify the relationship between the land use and water yield. The study area is the Atibainha watershed $\left(140 \mathrm{~km}^{2}\right)$ that, together with more 3 watersheds, water supply 13 million people in São Paulo and Campinas cities. The land use maps were derived from 1988, 1993, 1996, 2001 and 2008 Landsat scenes classification. The hydrological analysis were derived from 30, 4560 and 75 daily discharge Absolute Minimum Flow analysis and total water year precipitation during 1986 and 2007 years. Linear regression analyses and non-parametric statistic test were used to identify the temporal changes in the discharge and precipitation trend. The results indicated that secondary Atlantic forest cover decrease from $38 \%$ to $21 \%$ and afforestation with Eucalyptos urophylla increase from $24 \%$ to $43 \%$. The totals of annual precipitation showed significant downward trend ( $p$-value $<0.001)$. During the same period, daily dry discharge presented a significance trend to decline in 30, 45,60 and 75 consecutive dry days presenting a decrease to $61 \%, 56 \%, 55 \%$ and $60 \%$ respectively ( $p$ value $<0.001)$. The results indicate that exist a water yield decrease trend during the dry season in the Atibainha watershed and this is directed related with the decreases in precipitation inputs.

Key words: afforestation, deforestation, dry period discharge, environmental impacts. 


\section{Introdução}

As incertezas no ramo da hidrologia em relação à conversão de uso das terras em áreas de floresta estão centralizadas na questão da escala. Estudos para verificar os impactos da conversão de uso das terras em bacias hidrográficas de até $1 \mathrm{~km}^{2}$ já foram vastamente explorados, destacando-se o estudo de bacias pareadas de Bosch and Hewlett (1982).

No entanto, estudos em bacias hidrográficas acima de dezenas de $\mathrm{km}^{2}$, na meso e macro escala, ainda são incipientes e, dos existentes, ainda apresentam dados discrepantes. As diferenças nos resultados estão associadas às diferenças nas proporções de conversão de uso das terras, nas novas formas de uso e respectivos manejos, na distribuição desigual da chuva no tempo e no espaço, nas condições de infiltração dos solos, etc.

Andreassian (2004), apresentou uma perspectiva histórica em relação às discordâncias em relação aos impactos hidrológicos das florestas. Segundo o autor, na Europa e nos países desenvolvidos, as conseqüências do desmatamento para a qualidade e quantidade de água já vem sendo discutidas desde a antiguidade, no entanto, ainda não existe um consenso de quais são os reais efeitos do desmatamento no regime hídrico das bacias hidrográficas, principalmente durante os eventos de cheia e estiagem.

Diante de tantas incertezas em relação aos reais efeitos da conversão de floresta para agricultura, Brown et al (2005) concluíram que, a causa essencial para o aumento dos eventos de cheia em áreas desmatadas não é exatamente a redução das área de floresta, mas sim as condições em que essa redução ocorreu.

Assim, estudos que visam identificar a evolução do uso das terras, suas atuais condições tais como procedimentos de manejo adotados nas novas formas de uso das terras e o comportamento da chuva e vazão durante um período em que os dados sejam coincidentes são de suma importância para o manejo dos recursos hídricos.

\section{Objetivos}

Identificar as possíveis alterações no regime hidrológico de bacia hidrográfica de médio porte em região montanhosa nos períodos de estiagem em função das alterações na paisagem.

\section{Área de estudo}

A bacia do Atibainha a montante do reservatório, localiza-se entre os paralelos $22^{\circ}$ $50^{\prime} 37.24^{\prime \prime} \mathrm{S}$ e $23^{\circ} 11^{\prime} 43.65^{\prime \prime} \mathrm{S}$ e os meridianos $46^{\circ} 01^{\prime} 56.20^{\prime \prime} \mathrm{W}$ e $46^{\circ} 17^{\prime} 31.12 \mathrm{~W}$, abrangendo uma área total de $140 \mathrm{~km}^{2}$ (Figura1). A área de estudo pertence à Serra da Mantiqueira, face ocidental, estando inserida na área de nascentes da bacia do rio Atibaia. O clima predominante é o tropical de altitude, com chuvas concentradas no verão e invernos secos. O índice de pluviosidade é influenciado pelas massas tropicais atlânticas, sendo a média anual 1800 mm/ano.

A área de estudos faz parte do Sistema Cantareira de Abastecimento de Água, que junto à outras três bacias hidrográficas, abastecem a região metropolitana de São Paulo (RMSP) e Campinas (RMC), um total de 13 milhões de pessoas.

A área de estudo está inserida numa região de rochas cristalinas pré-cambrianas que apresentam relevo declivoso.

Nessa região, o desmatamento das florestas naturais de mata atlântica ocorreu no século XIX para abrigar as plantações de café. A crise cafeeira de meados do século XX impulsionou a transição da cultura cafeeira para a pastagem, pois na época, as altas declividades eram um empecilho para a agricultura mecanizada. 


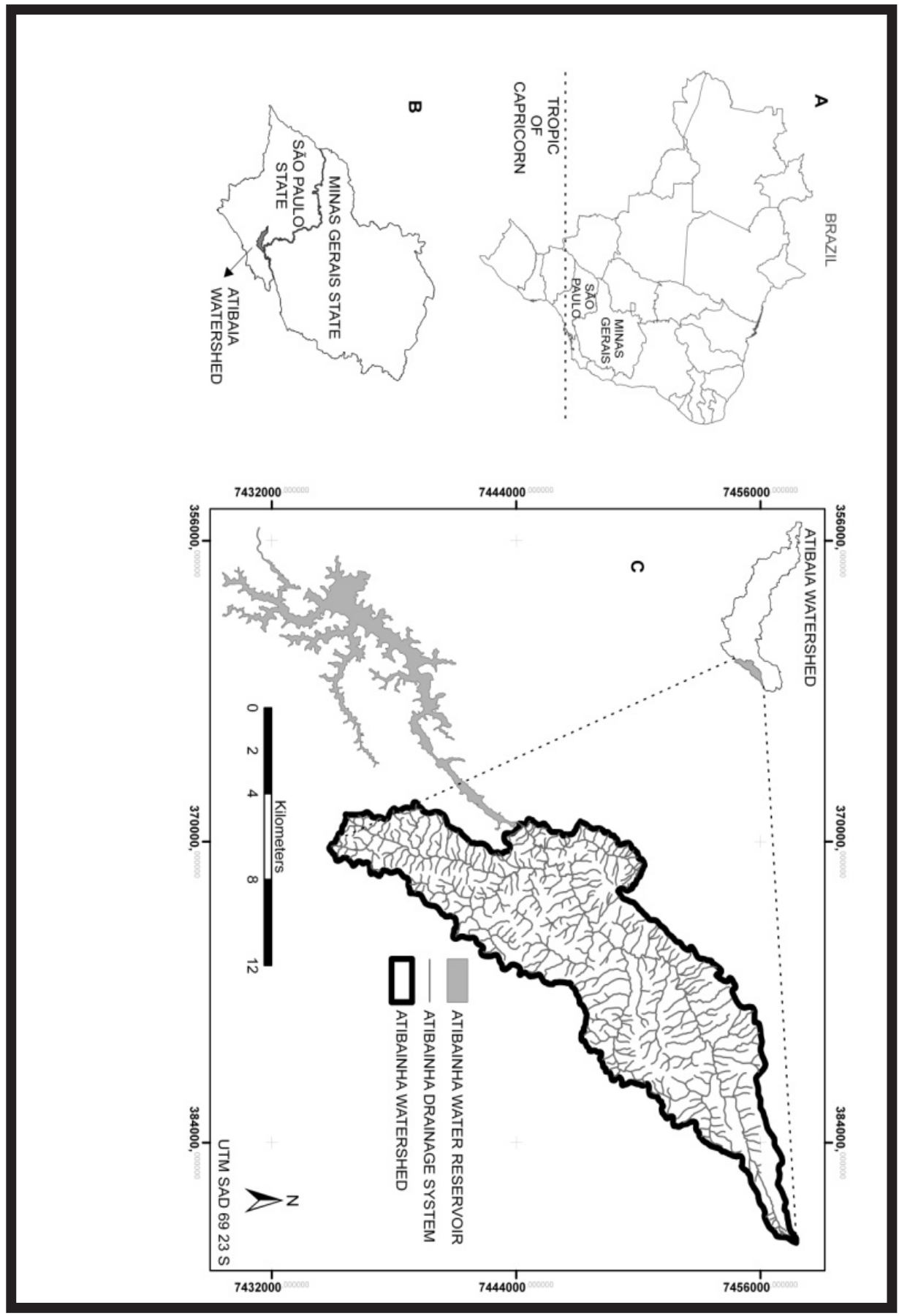

Figura 1: Localização da bacia do Atibaia no Brasil (A), nos estados de São Paulo e Minas Gerais (B) e a bacia do Atibainha (C). 


\section{Materiais e métodos}

Materiais:

- Imagens dos sensores Landsat TM e ETM nas datas 12/09/1988, 24/07/1993, $13 / 05 / 1996,03 / 05 / 2001,17 / 07 / 2008$, com as bandas 3, 4 e 5, para os mapas de uso e ocupação das terras.

- Série histórica dos anos de 1985 a 2007 dos totais diários de chuva e vazão dos postos de monitoramento da SABESP (Companhia de Saneamento Básico do Estado de São Paulo), cuja localização encontra-se na saída do reservatório.

\section{Método}

\section{Uso das terras}

Para a definição das evolução dos tipos de uso e ocupação das terras, utilizouse uma série histórica de imagens Landsat TM (1988, 1993, 1996, 2001 e 2008) em períodos secos. O processamento das imagens consistiu em três etapas: georreferenciamento, classificação supervisionada, confirmação com dados de campo e correção das falhas da classificação anterior ao campo.

\section{Séries de chuva e vazão}

Para avaliar a evolução dos totais anuais de chuva consideramos totais anuais do ano hidrológico (setembro a outubro). Para verificar a existência de tendências na série de chuva ao longo dos anos considerados, utilizamos o teste de Mann Kendall (estatística não-paramétrica).

Para avaliar a evolução das vazões no período de seca, aplicamos um filtro com a técnica da média móvel de 7 dias para eliminação dos ruídos de leituras existentes na série de dados. Posteriormente, registramos os valores de vazão, no último dia de cada intervalo de estiagem considerado, sendo 30, 45, 60 e 75 dias sem chuva. Neste trabalho, consideramos como dias de chuva eventos acima de $10 \mathrm{~mm} /$ dia. A seguir, aplicamos os testes de Mann Kendall e Pettit, conforme trabalhos de Back (2001) e Mortatti et al (2004).

\section{Resultados \\ Uso das Terras}

A Tabela 1 apresenta os resultados da classificação supervisionada de uso das terras em 1988, 1993, 1996, 2001 e 2008. As classes de uso das terras em todos os anos analisados foram mata nativa, silvicultura, pastagem, capoeirão e estradas.

\begin{tabular}{|c|c|c|c|c|c|}
\hline \multirow[b]{2}{*}{ Classes de uso } & \multicolumn{5}{|c|}{ Porcentagem (\%) das classes de uso das terras na Bacia do Atibainha } \\
\hline & Ano 1988 & 1993 & 1996 & 2001 & 2008 \\
\hline Mata nativa & 38 & 28 & 25 & 23 & 21 \\
\hline Silvicultura & 24 & 34 & 42 & 42 & 43 \\
\hline Pastagem & 22 & 23 & 19 & 26 & 25 \\
\hline Capoeirão & 12 & 11 & 10 & 5 & 7 \\
\hline Estradas & 4 & 4 & 4 & 4 & 4 \\
\hline
\end{tabular}

Tabela 1: Relação das porcentagens das classes de uso das terras na bacia do Atibainha. 
Os resultados do uso das terras demonstraram que nas 5 datas analisadas a área de estudo possui fragmentos de mata nativa/ secundária, reflorestamento com Eucalyptos urophylla, pastagem e áreas abandonadas denominadas capoeirão. Entre as datas de 1988 e 2008 ocorreram modificações nos usos das terras e suas proporções.

Durante o período de 20 anos, de 1988 a 2008, a pastagem foi a atividade que pouco se alterou. A principal mudança no uso das terras foi em relação à silvicultura e à mata nativa. A silvicultura aumentou de $24 \%$ em 1988 para $43 \%$ em 2008. E a mata nativa diminuiu, passando de $38 \%$ em 1988 para 21\% em 2008, evidenciando desmatamentos associados à silvicultura.

As velocidades de desmatamento entre cada intervalo das classificações de uso das terras (Tabela 2) indicam que entre 1988 e 1993 ocorreram os maiores índices de desmatamentos, com 2,4 km²/ano. Em relação às velocidades de incremento das áreas de silvicultura, o intervalo de 1993 a 1996 registrou o maior índice, com 2,8 $\mathrm{km}^{2} /$ ano.

\begin{tabular}{|lcc|}
\hline & $\begin{array}{l}\text { Velocidade de desmatamento } \\
\left(\mathbf{K m}^{2} / \mathbf{a n o}\right)\end{array}$ & $\begin{array}{l}\text { Velocidade de incremento das } \\
\text { áreas de silvicultura (Km } \mathbf{~ / a n o})\end{array}$ \\
\hline 1988 a 1993 (6 anos) & 2,4 & 2,4 \\
\hline 1993 a 1996 (4 anos) & 0,9 & 2,8 \\
\hline 1996 a 2001 (6 anos) & 0,5 & 0,02 \\
\hline 2001 a 2008 (8 anos) & 0,4 & 0,1 \\
\hline
\end{tabular}

Tabela 2: Velocidades de desmatamento e de incremento de áreas de silvicultura entre cada intervalo das classificações de uso das terras em $\mathrm{km}^{2} / \mathrm{ano}$

A evolução do uso das terras e os índices de desmatamento e crescimento das áreas de silvicultura indicam que as áreas de mata nativa estão sendo substituídas por silvicultura na bacia do rio Atibainha.

Em relação ao manejo das áreas de silvicultura na bacia do Atibainha, Pereira e Teixeira Filho (2009) identificaram que não existe planejamento nem assistência técnica para os agricultores. A finalidade da silvicultura é para a produção de lenha e carvão, fonte energética para abastecer padarias e pizzarias na região metropolitana de São Paulo. O corte das toras é realizado de 4 a 5 anos, com utilização de fogo para eliminação dos galhos mais finos. A espécie das plantações é a Eucalyptos urophylla e as plantações das mudas são preferencialmente realizadas no período de chuvas.

\section{Séries de chuva e vazão}

A figura 2 apresenta a evolução dos totais anuais do ano hidrológico da série de chuvas diárias no período de 1985 a 2007. A regressão linear da série de chuva indica tendência de decréscimo. A variação relativa da chuva ao longo dos 23 anos hidrológicos observados, foi de $3.6 \%$. 


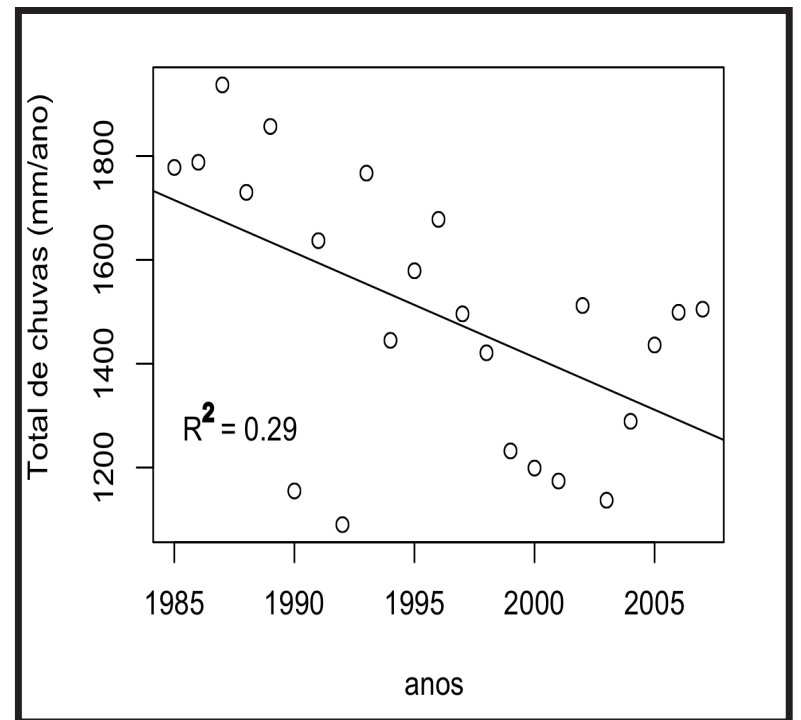

Figura 2: Regressão linear da série do comportamento regional dos totais anuais do ano hidrológico na bacia do rio Atibainha.

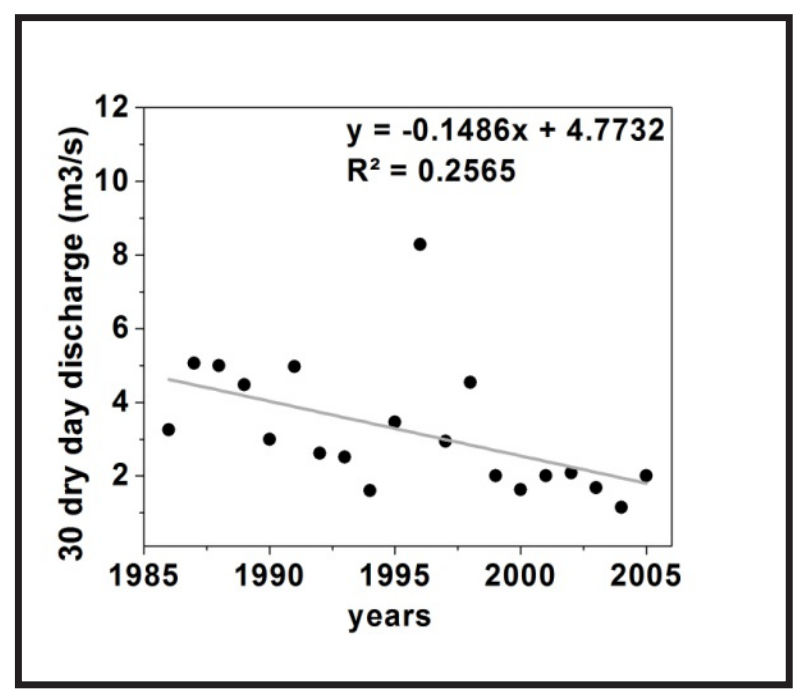

O gráfico da Figura 2 indica que existe tendência de decréscimos no comportamento das chuvas durante o intervalo estudado. O teste de Mann Kendall confirma que a tendência negativa para a série de chuvas é significativa pois o p_value é $<0.001$.

Os resultados das vazões mínimas para os períodos de estiagem de 30 e 45 dias estão apresentados na Figura 3 e os de 60 e 75 dias estão na Figura 4.

A regressão linear das vazões em 30 e 45 dias de estiagem indicam que está havendo uma tendência de decréscimo de $61 \%$ para 30 dias (Figura 3a), de 56\% para 45 dias (Figura 3b) e que os menores valores registrados se iniciam a partir do ano hidrológico de 1999/2000, no qual ocorre uma queda brusca nas vazões mínimas. A estatística de Mann Kendall indica que em 30 e 45 dias de estiagem a tendência de decréscimo é significativa, com p_value $<0.001$.

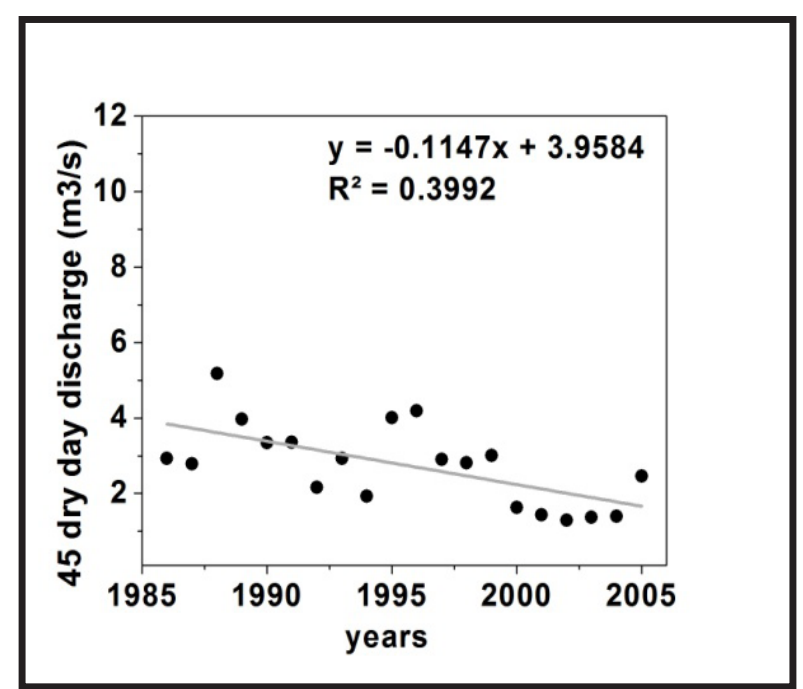



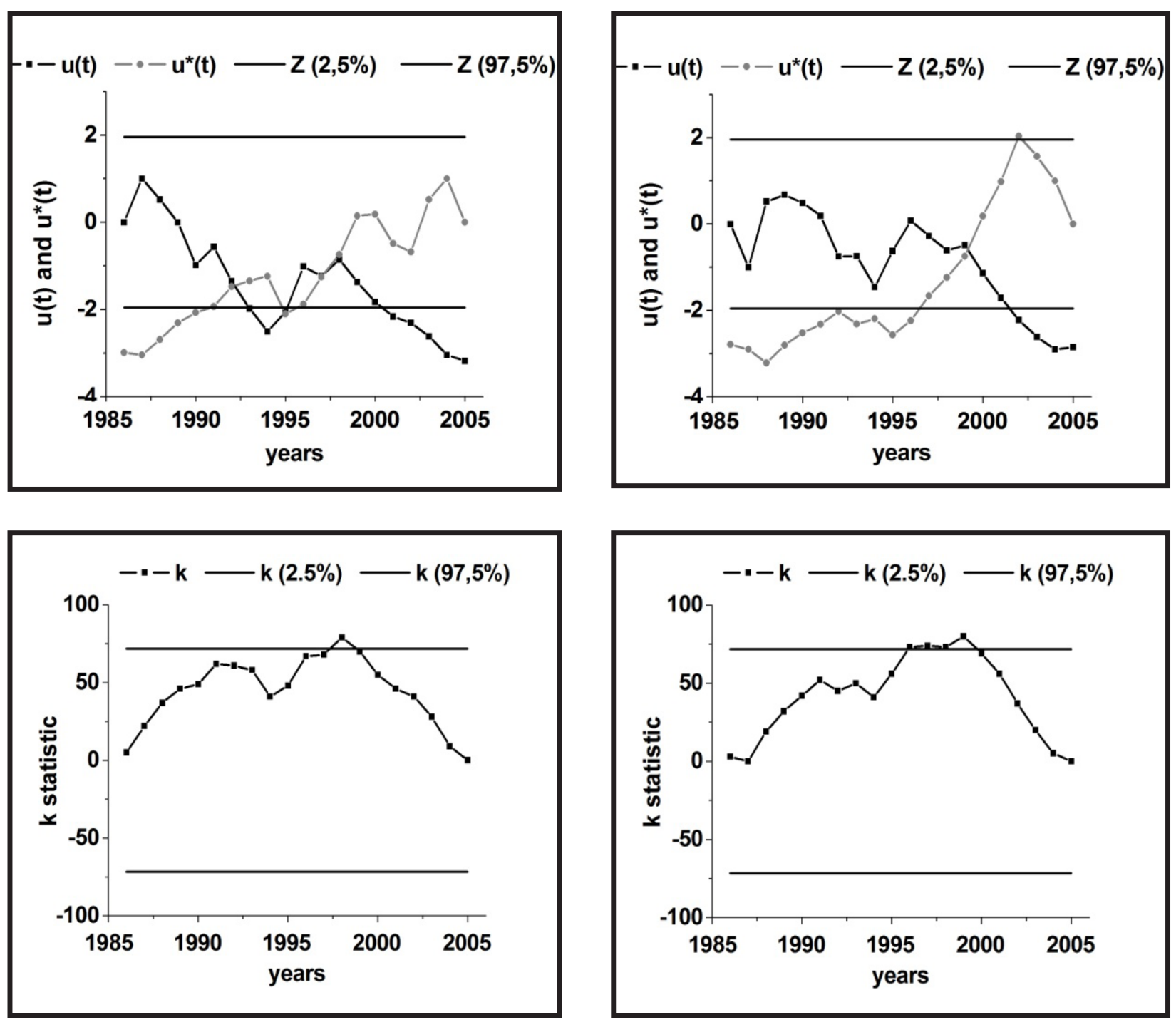

Figura 3: Regressão linear da série de vazões mínimas em 30 e 45 dias de estiagem (3a e 3b) e respectivas análises estatísticas de Mann Kendall (3c e 3d) e Pettit (3e e 3f). 
No entanto, analisando o gráfico da estatística de Mann Kendall (Figuras 3c e 3d) para as vazões de 30 e 45 dias de estiagem, observase que a tendência de decréscimo das vazões em 30 dias não é significativa devido aos múltiplos cruzamentos de $u(t)$ e $u^{*}(t)$ e que em 45 dias a tendência de decréscimo é significativa a partir do ano de 2001.

No entanto, embora a estatística de Mann Kendall não indique tendência significativa de queda para as vazões de 30 dias, a estatística de Pettit indica que existe um ponto de mudança
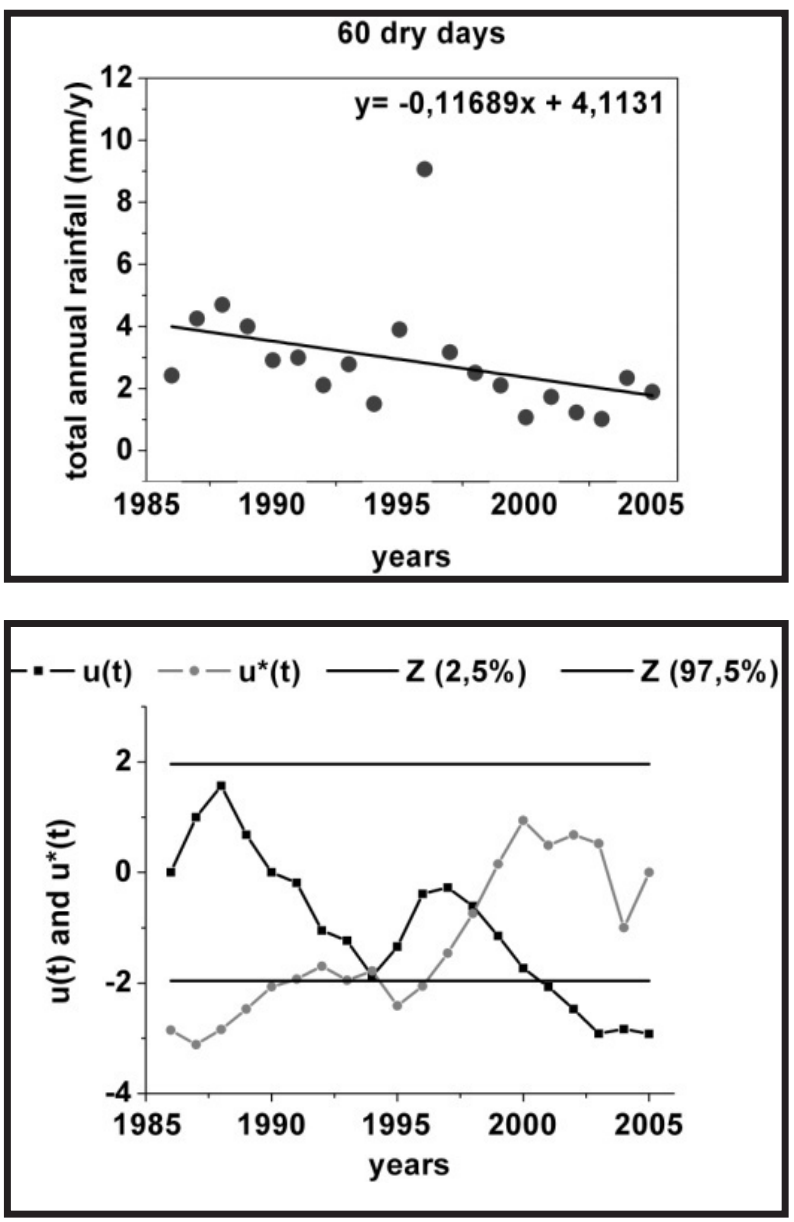

brusca nos valores a partir do ano de 1997/1988? tanto para 30 quanto para 45 dias (Figuras 3 e e $3 f$ ).

A regressão linear das vazões em 60 e 75 dias de estiagem indicam que está havendo uma tendência de decréscimo de $55 \%$ para 60 dias, de $60 \%$ para 75 dias (Figuras $4 a$ e 4 b) e que os menores valores registrados se iniciam a partir do ano hidrológico de 1999, no qual ocorre uma queda brusca nas vazões mínimas. A estatística de Mann Kendall demonstrou que existe tendência de decréscimo significativa para 60 e 75 dias de estiagem com p_value $<0.001$.
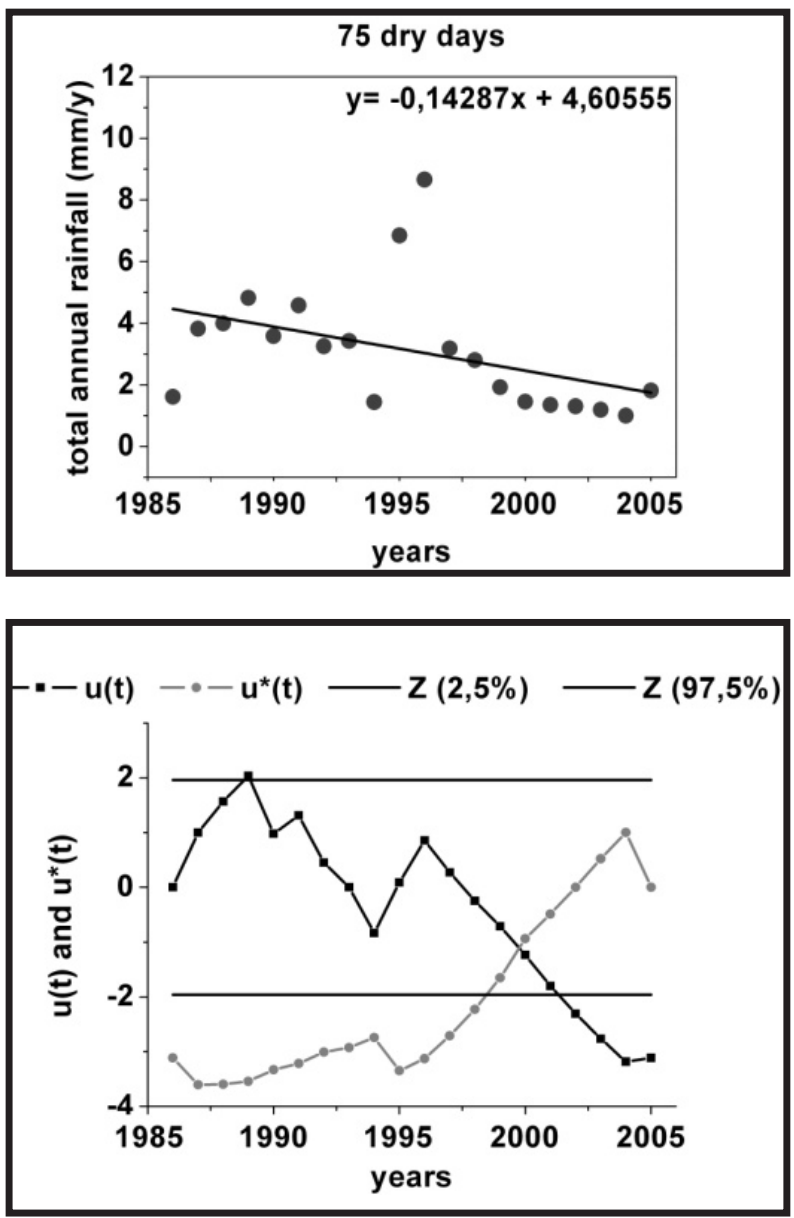

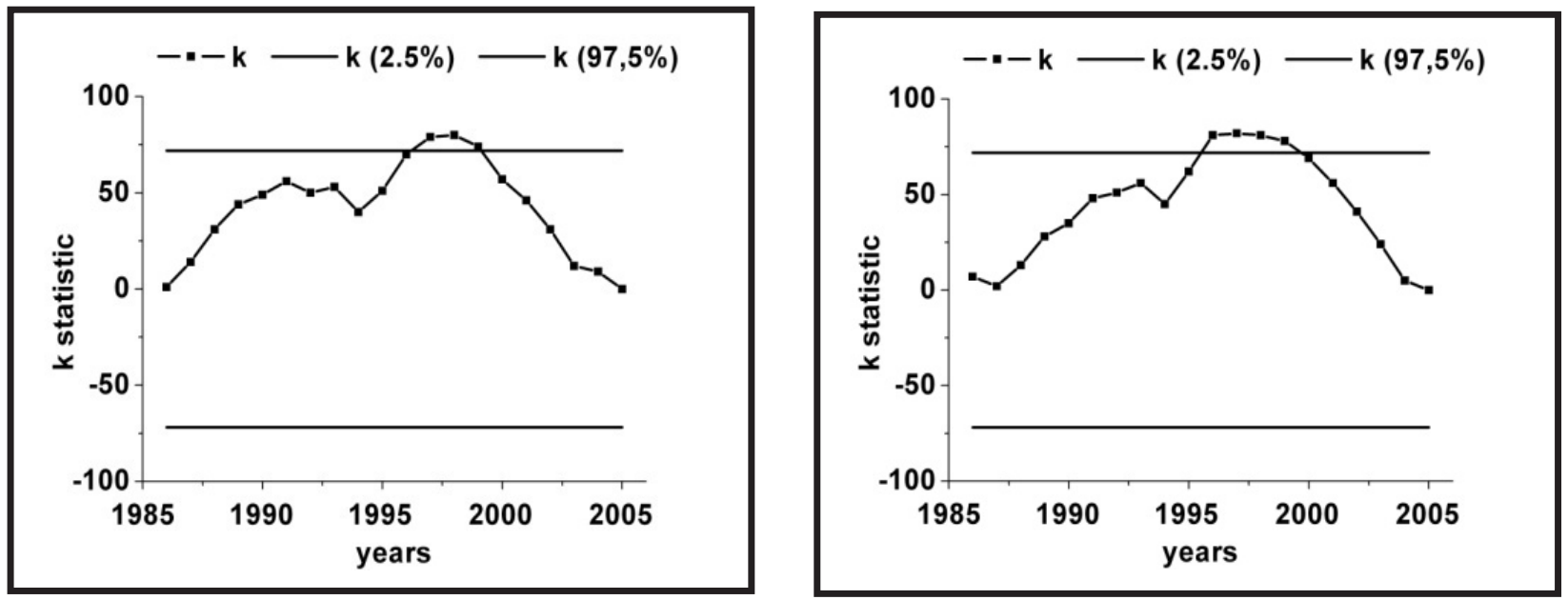

Figura 4: Regressão linear da série de vazões mínimas em 30 e 45 dias de estiagem (4a e 4b) e respectivas análises estatísticas de Mann Kendall (4c e 4d) e Pettit (4e e 4f).

No entanto, analisando o gráfico da estatística de Mann Kendall (Figura 4c e 4d) para as vazões de 60 e 75 dias de estiagem, observase que a tendência de decréscimo das vazões em 60 dias não é significativa devido aos múltiplos cruzamentos de $u(t)$ e $u^{*}(t)$ e que em 75 dias a tendência de decréscimo é significativa a partir do ano de 2001.

Embora a estatística de Mann Kendall não indique tendência significativa de queda para as vazões de 60 dias, a estatística de Pettit indica que existe um ponto de mudança brusca nos valores a partir do ano de $1996 / 1997$, tanto para 60 quanto para 75 dias (Figura 4e e 4f).

\section{Discussão dos resultados}

Os resultados das alterações de uso das terras, tais como as velocidades de desmatamento e a conversão de uso das terras para silvicultura, associadas às práticas agrícolas adotadas nos últimos 21 anos na área de estudo, indicam que os processos de escoamento superficial provavelmente estão sendo alterados.

No entanto, o desmatamento não parece ser o principal responsável pela diminuição das vazões na estiagem. Primeiro porque o desmatamento ocorreu de forma gradual ao longo do intervalo estudado, dissipando os efeitos de solo exposto ao longo dos anos. E, segundo, porque as maiores perdas de água das bacias hidrográficas são via evapotranspiração. Assim, quando há a retirada da mata em uma bacia hidrográfica, normalmente, as vazões aumentam durante a estiagem, devido às quedas nas taxas de evapotranspiração (Zhang et al., 2001).

Podemos ainda considerar que as diminuições das vazões estão relacionadas às práticas agrícolas utilizadas nas plantações de eucalipto. Gafur et al (2003) avaliaram os efeitos dos cortes de madeira em bacia de1 hectare (bacia de pequeno porte) utilizando fogo e concluíram que o escoamento superficial anual obteve um aumento de $16 \%$ após os cortes e as perdas de solo foram 6 vezes maiores do que o período anterior ao corte. Os efeitos de aumento na vazões de pico e, conseqüentemente, diminuição nos coeficientes de escoamento superficial, também foram encontrados por Waterloo et al (2007) após colheita de madeira. No entanto, ambos os autores citados neste parágrafo não identificaram diminuição nas vazões durante a estiagem.

Cosandey et al. (2005) conclui que o solo exposto é importante fator de alterações hidrológicas. O solo estando com cobertura vegetal, 
seja com vegetação nativa, seja com pastagem ou culturas agrícolas, apresenta condições boas condições para infiltração da água das chuvas.

Os efeitos do manejo da silvicultura na bacia do Atibainha parecem se diluir ao longo dos anos, não sendo suficiente para alterar as vazões na estiagem. Segundo Smakhtin (2001) não existe relato na literatura de diminuições nas vazões durante estiagem devido à diminuições na capacidade de infiltração.

Costa et al (2003) identificou aumento de $24 \%$ nas vazões anuais, de $3 \%$ nas chuvas e de $20 \%$ nos coeficientes de escoamento superficial após conversão de floresta para pastagem entre 1960 e 1995. Em relação ao período seco e chuvoso, Costa et al (2003) identificou que as vazões aumentaram $52 \%$ nas cheias mas não apresentaram mudanças significativas na estiagem.

Lin e Wei (2008), em bacia de 2860 km2, avaliaram impactos hidrológicos do corte de pinus ( $30 \%$ da área da bacia) e identificaram que, estatisticamente, os aumentos das médias anuais e de pico nas vazões estavam correlacionadas com a quantidade das áreas de corte, no entanto, as vazões de estiagem não apresentaram mudanças significativas. Siriwardena et al (2006) estudou os impactos das mudanças de uso das terras numa bacia hidrográfica de $16.440 \mathrm{~km}^{2}$ na Austrália no período de pré e pós desmatamento. Os autores identificaram que no período pós desmatamento, o escoamento aumentou em $78 \%$ em relação ao período anterior ao desmate. A área de floresta foi reduzida de $82 \%$ da área da bacia para $38 \%$. Novamente, os autores não identificaram mudanças significativas na estiagem.

Wilk et al (2001), não indicaram alterações significativas nos regimes de chuva, escoamento e vazões em áreas com intenso desmatamento (redução de 80 para $27 \%$ de mata nativa em 30 anos) em bacias de médio porte. Segundo Wilk et al (2001), a explicação é o crescimento de vegetação secundária nas áreas desmatadas, que acaba por reverter o processo de alteração no regime hídrico das bacias em função dos desmatamentos.

Lal (1997) em seus estudos na Nigéria demonstrou que os impactos do desmatamento iniciam-se no primeiro ano seguido do desmatamento e tendem a decair conforme o solo se regenera com as novas culturas.

Estudos que analisaram os impactos de atividades de reflorestamentos (Pinus $e$ Eucalyptus) indicaram alterações nas vazões durante o período de estiagem tais como Lane et al. (2005) e Sikka et al (2003). A justificativa para as alterações nos períodos de estiagem durante o crescimento das espécies de Pinus e Eucalyptus é pelo aumento da transpiração, principalmente em regiões tropicais e subtropicais.

Almeida and Soares (2003) identificaram que os picos das perdas por evapotranspiração em eucalipto, similares às perdas de mata atlântica, ocorrem quando as mudas atingem 7 anos de idade ou mais. Considerando o ciclo curto de corte das mudas, de 5 anos, nas plantações de eucalipto na bacia do Atibainha, pode-se constatar que, neste caso, as árvores não atingem idade suficiente para que ocorra as maiores perdas por evapotranspiração.

A evapotranspiração também está relacionada à disponibilidade de água. Segundo Stape, et al. (2004) as taxas de evapotranspiração estão diretamente relacionadas às precipitações e, em períodos de estiagem, normalmente as plantas apresentam controle estomático, diminuindo seu crescimento e, conseqüentemente, o uso de água.

Os resultados indicam que as diminuições das vazões na estiagem da bacia do Atibainha não estão diretamente relacionadas às perdas por escoamento superficial e subsuperficial. O ciclo curto de corte dos eucaliptos, segundo estudos anteriores, também não chega a atingir os estágio agressivos de evapotranspiração, a ponto de secar o lençol freático. As diminuições nos totais de chuvas parecem ser o principal fator das alterações nas vazões.

\section{Considerações finais}

Os resultados indicam que as diminuições das vazões na estiagem da bacia do Atibainha não estão diretamente relacionadas às mudanças de uso das terras via aumento das taxas de escoamento superficial e sub-superficial. As diminuições nos totais de chuvas parecem ser o principal fator encontrado para explicar as alterações nas vazões durante a estiagem. 
No entanto, é necessário um estudo mais detalhado das condições de infiltração (solos e geologia) e evapotranspiração das novas espécies, no caso eucaliptus urophyla, para definir o quanto o desmatamento e as novas culturas estão interferindo no regime hidrológico. Tais estudos são de suma importância para ações efetivas de planejamento ambiental, especialmente na gestão de bacias hidrográficas.

\section{Bibliografia}

Almeida, A.C. and Soares, J.V., 2003. Comparação entre uso de água em plantações de Eucalyptus grandis e floresta ombrófila densa (Mata Atlântica) na costa leste do Brasil. Revista Árvore, 27(2): 159-170.

Andreassian, V., 2004. Waters and forests: from historical controversy to scientific debate. J Hydrol, 291(1-2): 1-27.

Back, A.J., 2001. Aplicação de análise estatística para identificação de tendências climáticas. Pesquisa agropecuária brasileira, 36(5): 717-726.

Bosch, J.M. and Hewlett, J.D., 1982. A review of catchment experiments to determine the effect of vegetation changes on water yield and evapotranspiration. Journal of Hydrology, 103: 323-333.

Brown, A., Zhang, L., McMahon, T., Western, A. and Vertessy, R., 2005. A review of paired catchment studies for determining changes in water yield resulting from alterations in vegetation. J Hydrol, 310(1-4): 28-61.

Cosandey, C. et al., 2005. The hydrological impact of the mediterranean forest: a review of French research. J Hydrol, 301(1-4): 235-249.

Costa, M., Botta, A. and Cardille, J., 2003. Effects of large-scale changes in land cover on the discharge of the Tocantins River, Southeastern Amazonia. J Hydrol, 283(1-4): 206-217.

Gafur, A., Jensen, J.R., Borggaard, O.K. and Petersen, L., 2003. Runoff and losses of soil and nutrients from small watersheds under shifting cultivation (Jhum) in the Chittagong Hill Tracts of Bangladesh. J Hydrol, 274(1-4): 30-46.
Lal, R., 1997. Deforestation effects on soil degradation and rehabilitation in western Nigeria. IV Hydrology and water quality. Land degradation and development, 8: 95-126.

Lane, P.N.J., Best, A.E., Hickel, K. and Zhang, L., 2005. The response of flow duration curves to afforestation. J Hydrol, 310(1-4): 253-265.

Lin, Y. and Wei, X., 2008. The impact of largescale forest harvesting on hydrology in the Willow watershed of Central British Columbia. J Hydrol, 359(1-2): 141-149.

Mortatti, J., Bortoletto Júnior, M.J., Milde, L.C.E. and Probst, J.L., 2004. Hidrologia dos Rios Tietê e Piracicaba: séries temporais de vazão e hidrogramas de cheia. Rev. de Ciência \& Tecnologia, Piracicaba, 12(23): 1-88.

Pereira, V.R. and Teixeira Filho, J., 2009. Identificação das áreas susceptíveis aos processos erosivos em duas bacias do Sistema Cantareira por meio de diferentes cenários. Acta Scientiarum. Agronomy Maringá, 31(1): 155-163.

Sikka, A., Samra, J., Sharda, V., Samraj, P. and Lakshmanan, V., 2003. Low flow and high flow responses to converting natural grassland into bluegum (Eucalyptus globulus) in Nilgiris watersheds of South India. J Hydrol, 270(1-2): 12-26.

Siriwardena, L., Finlayson, B.L. and McMahon, T.A., 2006. The impact of land use change on catchment hydrology in large catchments: The Comet River, Central Queensland, Australia. J Hydrol, 326(1-4): 199-214.

Smakhtin, V.U., 2001. Low flow hydrology: a review. J Hydrol, 240(3-4): 147-186. 
Stape, J., Binkley, D. and Ryan, M., 2004. Eucalyptus production and the supply, use and efficiency of use of water, light and nitrogen across a geographic gradient in Brazil. Forest Ecol Manag, 193(1-2): 17-31.

Waterloo, M.J., Schellekens, J., Bruijnzeel, L.A. and Rawaqa, T.T., 2007. Changes in catchment runoff after harvesting and burning of a Pinus caribaea plantation in Viti Levu, Fiji. Forest Ecol Manag, 251(1-2): 31-44.
Wilk, J., Andersson, L. and Plermkamon, V., 2001. Hydrological impacts of forest conversion to agriculture in a large river basin in northeast Thailand. Hydrological Processes, 15(14): 27292748.

Zhang, L., Dawes, W.R. and Walker, G.R., 2001. Response of mean annual evapotranspiration to vegetation changes at catchment scale. Water Resour Res, 37(3): 701-708. 